\title{
EFECTOS TÓXICOS DEL CONTENIDO DE DOS TAMAÑOS DE QUISTES DE Sarcocystis aucheniae EN CONEJOS INOCULADOS EXPERIMENTALMENTE
}

\author{
Toxic Effects of the Contents of Two cyst Sizes of Sarcocystys aucheniae \\ in EXPERIMENTALLY INOCULATED RABBits
}
María Chileno M. ${ }^{1}$, Amanda Chávez V. ${ }^{1,2}$, Eva Casas A. ${ }^{1}$, Alfonso Chavera C. ${ }^{3}$, Nidia Puray C. ${ }^{1}$

\section{Resumen}

\begin{abstract}
El objetivo del estudio fue determinar los efectos tóxicos de dos tamaños de macroquistes de Sarcocystis aucheniae (>5 mm y 1-3 mm) en conejos inoculados experimentalmente, a través del tiempo de supervivencia, manifestaciones clínicas y alteraciones anatomopatológicas. Se colectaron macroquistes del cuello de alpacas procedentes del camal de Huancavelica. Las concentraciones de proteínas antigénicas para los macroquistes grandes y pequeños, medidas por el método de Biuret, fueron de 3.3 y 2.4 $\mathrm{mg} / \mathrm{mL}$, respectivamente. Se utilizaron 52 conejos, de los cuales 25 fueron inoculados con extractos de macroquistes grandes, 25 con extractos de macroquistes pequeños y 2 quedaron como controles. Cada grupo tratado estuvo compuesto por cinco subgrupos de conejos, a quienes se aplicó dosis de 2.5, 5, 10, 15 y $25 \mu \mathrm{g}$ de proteína por kilogramo de peso vivo, vía IM. La evaluación del tiempo de supervivencia se hizo hasta las 72 h posinoculación. El tiempo promedio de mortalidad ocurrió a las 7 h post-inoculación y la dosis de mayor letalidad fue de 15 ?g/kg. Las manifestaciones clínicas más frecuentes fueron hipertermia, taquipnea, diarrea, inapetencia, incoordinación y postración. La principal lesión en la necropsia fue congestión de vasos sanguíneos en cerebro y otros órganos, así como presencia de líquido en las cavidades abdominal, torácica y pericárdica. Además, se observó daño degenerativo en cerebro, hígado y riñón, y edema cerebral. No se observaron alteraciones en músculo esquelético. La severidad de las lesiones estuvo relacionada al tamaño de quiste, siendo más severas con los quistes pequeños. Se encontró diferencia estadística $(\mathrm{p}<0.05)$ en el tiempo de supervivencia de los conejos por efecto de la dosis y tamaño de los macroquistes, observándose el $96 \%$ de supervivencia para los animales inoculados con macroquistes grandes y el $68 \%$ para los pequeños.
\end{abstract}

Palabras clave: sarcocistiosis, macroquistes, toxicidad, alpacas, conejos

\footnotetext{
${ }^{1}$ Laboratorio de Microbiología y Parasitología Veterinaria, ${ }^{2}$ Laboratorio de Histopatología, Embriología y Patología Veterinaria, Facultad de Medicina Veterinaria, Universidad Nacional Mayor de San Marcos, Lima
} 
The aim of this study was to determine the toxic effects of two macrocyst sizes of Sarcocystis aucheniae ( $>5 \mathrm{~mm}$ and $1-3 \mathrm{~mm}$ ) in experimentally inoculated rabbits through survival time, clinical signs, and pathological changes. Macrocysts from alpaca necks were collected in the slaughterhouse of Huancavelica, Peru. Antigenic proteins concentrations from large and small macrocysts, measured by the Biuret method were 3.3 and $2.4 \mathrm{mg} / \mathrm{mL}$, respectively. Twenty five rabbits were inoculated with extracts from large macrocysts, 25 with extracts from small macrocysts and 2 animals were used as controls. Each treatment group was formed by 5 subgroups of 5 rabbits each, which received, via IM, doses of $2.5,5,10,15$, and $25 ? \mathrm{~g}$ of protein per kg of body weight. Survival time was evaluated until 72 hours post inoculation. The average interval to death was $7 \mathrm{~h}$ and the more severe lethal dose was 15 ?g/kg. The most frequent clinical signs were hyperthermia, tachypnea, diarrhea, inappetence, incoordination, and recumbency. The principal lesion at necropsy was congestion of blood vessels in brain and other organs, and fluid in the abdominal, thoracic, and pericardial cavities. Also, degenerative lesions in brain, liver and kidney as well as brain oedema were found. Changes in skeletal muscle were not observed. The severity of injuries was related to size cyst, being worse with small cysts. Statistical difference $(p<0.05)$ in survival time due to the effect of dose and size of macrocyst was found. There were $96 \%$ survival for animals inoculated with large macrocysts and $68 \%$ for those inoculated with small macrocysts.

Key words : sarcocystiosis, macrocystic, toxicity, alpacas, rabbits

\section{INTRODUCCIÓN}

La sarcocistiosis es una infección parasitaria causada por varias especies de protozoos del género Sarcocystis, parásitos de amplia distribución mundial (Cordero del Campillo et al., 1999). Su ciclo de vida es indirecto, de tipo predador-presa, donde los hospederos definitivos son carnívoros y actúan como predadores y los hospederos intermediarios son sus presas. La infección en el hospedero definitivo se realiza por la ingestión de carne infectada con formas quísticas de Sarcocystis sp, y en el intermediario por ingestión de ooquistes eliminados con las heces del hospedero definitivo (Quiroz, 2000).

La sarcocistiosis presente en los camélidos sudamericanos (CSA) es causada por las especies $S$. lamacanis, S. aucheniae y $S$. guanicoecanis, siendo de mayor importancia la ocasionada por S. aucheniae debido a los quistes macroscópicos de color blanco que produce, principalmente en el esófago, cuello, costillares, brazuelo, lomo y pierna (Guerrero et al., 1967; Castro, 1974; White, 1998). Este protozoo ocasiona importantes pérdidas económicas para la industria alpaquera, al ocasionar una disminución en la producción y la productividad del animal, además de generar pérdidas por los decomisos de carcasa (Leguía et al., 1989).

Los quistes de Sarcocystis tienen en su interior una sustancia proteica, denominada sarcocistina, con actividad neurotóxica (Hiepe et al., 1981). La sarcocistina es considerada como una endotoxina que actúa a nivel del músculo cardiaco y tejido nervioso gastrointestinal (Briggs y Foreyt, 1985). Los cuadros clínicos causados por esta toxina se han venido estudiando en las últimas décadas (Leguía, 2003). Se ha demostrado su acción letal en conejos utilizando proteínas de bradizoitos de quistes de $S$. aucheniae 
obtenidas por sonicación (Sam et al., 1998), así como con proteínas de quistes obtenidas de carne tratada física y químicamente (Céspedes, 2004).

Cornejo et al. (2007) encontraron discrepancias biológicas entre macroquistes de $S$. aucheniae de 2 tamaños (pequeños: 1-3 mm y grandes: $>5 \mathrm{~mm}$ ) al infectar canes, tanto en la duración del periodo prepatente y en la carga de esporoquistes eliminados, como en el porcentaje de mortalidad; sin embargo, el uso de estos dos tamaños de macroquistes de $S$. aucheniae, con fines diagnósticos, requiere de evaluaciones previas de la inocuidad del inóculo y la respuesta inmune que genera.

El objetivo del presente estudio fue determinar los efectos tóxicos de dos tamaños de quistes de $S$. aucheniae ( $>0.5$ $\mathrm{mm}$ y 1-3 $\mathrm{mm}$ ) en conejos inoculados experimentalmente, evaluando las manifestaciones clínicas y alteraciones anatomopatológicas en función a las dosis administradas.

\section{Materiales y Métodos}

\section{Material Biológico y Lugar de Estudio}

Se utilizaron cuellos de alpacas infectadas naturalmente con macroquistes de $S$. aucheniae y que fueron beneficiadas en el camal de Huancavelica. Los macroquistes se clasificaron por su tamaño en pequeños $(1-3 \mathrm{~mm})$ y grandes $(>5 \mathrm{~mm})$. El procesamiento para la obtención de antígenos se realizó en el Laboratorio de Parasitología de la Facultad de Medicina Veterinaria (FMV) de la Universidad Nacional Mayor de San Marcos (UNMSM), Lima.

Se utilizaron 52 conejos de la raza Nueva Zelanda, de 2 a $3 \mathrm{~kg}$ de peso y de 3 meses de edad, procedentes del bioterio de la FMVUNMSM. Se les practicó un análisis coproparasitológico seriado para descartar la presencia de parásitos gastrointestinales. Cincuenta conejos se distribuyeron en dos grupos experimentales y dos conejos se emplearon como controles no tratados.

\section{Preparación de Extractos Quísticos}

Se colectaron macroquistes de la musculatura esquelética cervical de las alpacas y se depositaron en PBS (solución buffer fosfato) a baja temperatura $\left(2-3{ }^{\circ} \mathrm{C}\right)$. Luego se lavaron con PBS y antibiótico (penicilina $100 \mathrm{UI}+$ estreptomicina $100 \mathrm{mg}$ ), y se clasificaron según su tamaño como macroquistes pequeños $(1-3 \mathrm{~mm})$ y grandes $(>5 \mathrm{~mm})$, empleando una regla esterilizada.

Se extrajo el contenido de los quistes con sumo cuidado. Se les sujetó con pinza plana en una canaleta, y el contenido fue absorbido con una jeringa de tuberculina. Los bradizoitos obtenidos se filtraron a través de una gasa estéril en un embudo, se les colocó en un tubo Falcón y se llevaron a una centrífuga refrigerada (Sorvall Super Speed RC2) a 500 rpm por 15 minutos, con PBS y antibiótico.

Se colectó el sedimento en un Beaker de $10 \mathrm{~mL}$ y se llevó al sonicador (Fisher modelo 300) por 60 ciclos por segundo en 4 intervalos de 30 segundos (Sam et al., 1998). El sonicado fue centrifugado a $14000 \mathrm{rpm}$ por 30 minutos, y el sobrenadante se pasó por un filtro de $0.22 \mathrm{~mm}$. Los filtrados se conservaron en congelación a $-20{ }^{\circ} \mathrm{C}$ en viales de $2 \mathrm{~mL}$. Los niveles de proteína de cada lote de antígeno fueron medidos por el método de Biuret. Paralelamente, se realizó un cultivo bacteriológico, para garantizar su esterilidad.

\section{Metodología Experimental}

Los conejos de cada uno de los dos grupos fueron inoculados intramuscularmente con proteína antigénica de macroquistes de $S$. aucheniae, recuperada de quistes pequeños y grandes, en dosis de $2.5,5,10,15$ y $25 \mu \mathrm{g} / \mathrm{kg}$, 
Cuadro 1. Temperatura corporal de conejos inoculados con diversas cantidades de proteína antigénica de macroquistes grandes $(>5 \mathrm{~mm})$ y pequeños $(1-3 \mathrm{~mm})$ de $S$. aucheniae

\begin{tabular}{ccccccc}
\hline \multirow{2}{*}{$\begin{array}{c}\text { Dosis } \\
(\mu \mathrm{g} / \mathrm{kg})\end{array}$} & \multicolumn{2}{c}{$\mathrm{T}^{\circ}$ pre-inoculación } & \multicolumn{2}{c}{$\begin{array}{c}\mathrm{T}^{\circ} \text { máxima post- } \\
\text { inoculación }\end{array}$} & \multicolumn{2}{c}{$\begin{array}{c}\text { Rango de la } \\
\text { presentación de la } \mathrm{T}^{\mathrm{y}} \\
\text { máxima (horas) }\end{array}$} \\
\cline { 2 - 7 } & Pequeño & Grande & Pequeño & Grande & Pequeño & Grande \\
\hline 2.5 & 38.2 & 38.7 & 40.3 & 40.3 & $2-7$ & $2-4$ \\
5 & 38.3 & 38.5 & 40.2 & 40.0 & $3-4$ & $4-8$ \\
10 & 38.6 & 38.4 & 40.0 & 40.0 & 3 & $2-4$ \\
15 & 38.1 & 38.3 & 40.2 & 40.5 & 3 & $3-4$ \\
25 & 38.4 & 38.6 & 40.5 & 40.3 & $2-3$ & $2-7$ \\
Control & 38.2 & 38.5 & & & & \\
\hline
\end{tabular}

Cuadro 2. Periodo (horas) de supervivencia de conejos inoculados con diversas cantidades de proteína antigénica de macroquistes grandes $(>5 \mathrm{~mm})$ y pequeños $(1-3 \mathrm{~mm}) \mathrm{de}$ S. aucheniae

\begin{tabular}{ccccccc}
\hline \multirow{2}{*}{ Tipo de macroquiste } & Conejo & \multicolumn{5}{c}{ Dosis de inoculación $(\mu \mathrm{g} / \mathrm{kg})$} \\
\cline { 3 - 7 } & 1 & 2.5 & 5 & 10 & 15 & 25 \\
\hline \multirow{3}{*}{ Pequeño } & 2 & 76 & 44 & 10 & 10 & 9 \\
& 3 & 72 & 9 & 7 & 8 & 8 \\
& 4 & 20 & 20 & 10 & 8 & 8 \\
& 5 & 19 & 12 & 9 & 8 & 7 \\
\hline \multirow{3}{*}{ Grande } & 1 & 72 & 72 & 13 & 17 & 13 \\
& 2 & 72 & 9 & 10 & 9 & 72 \\
& 3 & 72 & 35 & 10 & 23 & 20 \\
& 4 & 72 & 39 & 11 & 20 & 19 \\
& 5 & 72 & 72 & 11 & 18 & 18 \\
\hline
\end{tabular}

disueltos en un volumen de inóculo de $1 \mathrm{~mL}$ de suero fisiológico. Los dos conejos controles recibieron únicamente suero fisiológico (1 $\mathrm{mL}$ ), vía intramuscular.
Los conejos fueron monitoreados por 72 horas. Se registró la temperatura rectal previamente a la inoculación y luego se hizo a intervalos de una hora. Se realizó la necrop- 
Cuadro 3. Tiempo (horas) de supervivencia de conejos $(\mathrm{n}=5$ por grupo) inoculados con diversas cantidades de proteína antigénica de macroquistes grandes $(>5 \mathrm{~mm})$ y pequeños (1-3 mm) de $S$. aucheniae

\begin{tabular}{cccccc}
\hline \multirow{2}{*}{$\begin{array}{c}\text { Dosis } \\
\mu \mathrm{g} / \mathrm{kg})\end{array}$} & Tamaño de & Media de & Error & \multicolumn{2}{c}{ Intervalo de confianza } \\
\cline { 5 - 7 } & macroquiste & supervivencia & estándar & Mínimo & Máximo \\
\hline \multirow{2}{*}{2.5} & Pequeño & $27^{\mathrm{a}}$ & 10 & 7 & 47 \\
& Grande & $72^{\text {la }}$ & - & - & - \\
\multirow{2}{*}{5.0} & Pequeño & $19^{\mathrm{a}}$ & 7 & 6 & 32 \\
& Grande & $45^{\mathrm{a}}$ & 11 & 24 & 66 \\
\multirow{2}{*}{10.0} & Pequeño & $9^{\mathrm{a}}$ & 1 & 8 & 10 \\
& Grande & $11^{\mathrm{a}}$ & 1 & 10 & 12 \\
\multirow{2}{*}{15.0} & Pequeño & $8^{\mathrm{a}}$ & 0 & 8 & 9 \\
& Grande & $17^{\mathrm{b}}$ & 2 & 13 & 22 \\
\multirow{2}{*}{25.0} & Pequeño & $8^{\mathrm{a}}$ & 0 & 7 & 9 \\
& Grande & $28^{\mathrm{a}}$ & 10 & 9 & 48 \\
\hline
\end{tabular}

${ }^{1}$ Todos los conejos sobrevivieron hasta la última medición (72 horas)

${ }^{a, b}$ Superíndices con letras diferentes indican que las medias son diferentes $(p<0.05)$

sia a los conejos que murieron por efecto de la inoculación, así como a los conejos que sobrevivieron el periodo experimental. Se evaluaron las lesiones y alteraciones anatómicas macroscópicas, y se colectaron muestras de pulmón, intestino delgado, riñón, hígado, bazo, ganglio poplíteo, cerebro y músculo. Los tejidos se colorearon con tinción convencional de H-E, para la evaluación histopatológica.

\section{Evaluación de la Toxicidad Antigénica}

Se consideró el número de animales que sobrevivieron. Se determinó el tiempo de supervivencia de los conejos inoculados en cada tratamiento considerándose 72 horas como el tiempo máximo de observación, a través del análisis tiempo a un evento (Curva de Kaplan Meier).

Se utilizaron las variables dosis, tamaño de macroquiste, tiempo de supervivencia y número de animales sobrevivientes para el análisis de Regresión de Cox, donde se determinó las variables estadísticamente significativas que intervienen en la supervivencia de los animales inoculados con los dos tamaños de macroquistes de $S$. aucheniae.

\section{Resultados}

El extracto quístico de $S$. aucheniae de los quistes pequeños (1-3 mm) y grandes ( $>5$ $\mathrm{mm}$ ) después del procesamiento (homogenizado, lisado y centrifugado) presentaron 2.4 y $3.3 \mathrm{mg}$ de proteína/mL, respectivamente.

Los signos clínicos mostrados para el grupo inoculado con macroquistes pequeños fueron de hipertermia, taquipnea, pupila contraída, lagrimeo, pérdida de apetito, diarrea, fiebre, salivación, incoordinación y postración. En el caso de los conejos inoculados con macroquistes grandes, los signos clínicos fueron similares, con la diferencia que los animales presentaron hipotermia previa a la 
muerte. La recuperación de los animales que sobrevivieron fue progresiva. Se inició con ingesta de agua y comida, mayor actividad y estabilización de la temperatura corporal. La temperatura promedio en los conejos inoculados se muestra en el Cuadro 1. La temperatura corporal se elevó a partir de las dos horas post-inoculación.

En el Cuadro 2, se observa que todos los conejos inoculados con macroquistes grandes a dosis de $2.5 \mu \mathrm{g} / \mathrm{kg}$ sobrevivieron al periodo experimental de 72 horas y en caso de los conejos inoculados con macroquistes pequeños solo sobrevivió el $20 \%$. Los porcentajes de mortalidad fueron de 68 y $96 \%$ para los conejos inoculados con quistes grandes y pequeños, respectivamente. Asimismo, pudo observarse que los animales inoculados con quistes grandes permanecieron más tiempo vivos que los inoculados con quistes pequeños (Cuadro 3).

Se observó la presencia de líquido en las cavidades abdominal, torácica y pericárdica, congestión intestinal, hepática y renal, timpanización de intestinos y ciego, pequeñas zonas hemorrágicas en la mucosa intestinal y gástrica, y moderado crecimiento del bazo. Las alteraciones más importantes se hallaron en el cerebro. La congestión de los vasos sanguíneos se presentaron en el $96 \%$ de animales inoculados con macroquistes pequeños y en el 56\% de animales inoculados con macroquistes grandes. La presencia de líquido en la cavidad craneana se halló en el 84 y $44 \%$ de animales inoculados con macroquistes pequeños y grandes, respectivamente.

El grado de las lesiones en los órganos fue dependiente de la dosis inoculada; es decir, a menor dosis se observaron alteraciones de leves a moderadas y mientras la dosis inoculada incrementaba las alteraciones observadas variaron de moderadas a severas:

- Cerebro: En la mayoría de los casos se observó un proceso neuronal degenerativo con edema perivascular y perineuronal, figuras de satelitosis y neuronofagia. En caso de los animales inoculados con macroquistes pequeños presentaron, además, microtrombos.

- Pulmón: Ambos grupos presentaron engrosamiento del septo alveolar, restos de polimorfos nucleares, leve a moderada congestión, enfisema y pequeñas áreas hemorrágicas.

- Hígado: Ambos grupos presentaron pérdida de la citoarquitectura trabecular, tumefacción turbia de los hepatocitos con presencia de múltiples focos de polimorfos nucleares, leve a moderada congestión de sinusoides y proliferación de los conductos biliares.

- Intestino: Se observó severa exfoliación de las vellosidades, pero de tamaño variable. También presentaron infiltración de células mononucleares, edema, congestión y pequeñas zonas hemorrágicas. En caso de los animales inoculados con macroquistes pequeños, se observó, además, microtrombos.

- Bazo: En la mayoría de conejos de los dos grupos se observó de leve a severa depleción linfoide, incremento de la pulpa roja, moderada a severa hemorragia, y edema interfolicular.

- Riñón: En ambos grupos se observó tumefacción turbia de los túbulos renales con obliteración de sus lúmenes. Los glomérulos mostraron de leve a moderado aumento de tamaño y congestión. Para los animales inoculados con macroquistes pequeños, la congestión en el área medular fue más severa que los inoculados con quistes grandes.

- Ganglio linfático: Presentaron, en su mayoría, hiperplasia folicular linfoide, moderada congestión y edema intrafolicular linfoide.

- Músculo: No se encontró cambios estructurales a nivel de fibras.

Se encontraron diferencias estadísticas $(p<0.05)$ con respecto al tiempo de supervivencia, dosis y tamaño de macroquistes. 


\section{Discusión}

Existen diferencias biológicas y antigénicas en base al tamaño de los macroquistes de $S$. aucheniae, las cuales han sido demostradas en canes (Cornejo et al., 2007) y en conejos (Romero, 2009); de allí la importancia y necesidad de evaluar los efectos tóxicos de los dos tipos de quistes, para usarlos como alternativa en la obtención de antisueros.

La composición exacta de la sarcocistina presente en los quistes de Sarcocystis no está bien definida y solo se conoce la actividad biológica de los extractos de quistes de diversas especies de Sarcocystis. Esta actividad varía según la especie del parásito o del hospedador y de la dosis de proteína antigénica (Hiepe et al., 1981; Saleque et al., 1991; Mansilla, 1993; Saito et al., 1995).

Los signos clínicos post-inoculación, identificados en el estudio, confirman el efecto tóxico del contenido antigénico de quistes de S. aucheniae en conejos (Mansilla, 1993). Dubey et al. (1989) señalan la probabilidad que algunos Sarcocystis se rompan con el tiempo y liberen los productos tóxicos como la sarcocistina. Esta toxina desarrolla su acción tóxico-degenerativa sobre el tejido circundante produciendo la calcificación del parásito y de la estructura que lo rodea. Asimismo, es posible que las sustancias liberadas estimulen la producción del factor de necrosis tumoral (TNF) (Hiepe, 1972), que promueve la fase aguda del proceso inflamatorio (Fayer y Jonhson, 1973; Dubey et al., 1989; Nakamura et al., 1999).

Dentro de los signos clínicos observados, la hipertermia observada fue similar a los hallados en otras especies de Sarcocystis (Mansilla, 1993; Saito et al., 1995; Céspedes, 2004; Godoy et al., 2007; Granados et $a l .$, 2007). Esta hipertermia puede atribuirse al mecanismo de defensa del organismo frente a la toxina. Asimismo, la taquipnea obser- vada es una manifestación clínica evidente frente a pequeñas elevaciones de temperatura, debido a un aumento del metabolismo para atender la mayor demanda periférica de oxígeno y de nutrientes (Guinart y López, 1997).

Las lesiones macroscópicas fueron compatibles con resultados presentados en otros reportes (Mansilla, 1993; Godoy et al., 2007). El daño degenerativo cerebral fue la lesión más importante observada en ambos grupos. La formación de microtrombos en animales inoculados con macroquistes pequeños y en aquellos inoculados con la dosis más alta de macroquistes grandes, debida a la coagulación intravascular causada por la toxina (Trigo, 1993), demuestra su capacidad neurotóxica.

Órganos detoxificadores como riñón e hígado sufrieron diversas alteraciones, debido a que sus células presentan un metabolismo muy activo y su función es la degradación de productos nocivos como las toxinas (Trigo, 1993). Los procesos degenerativos observados en los órganos son modificaciones celulares debido a la alteración del equilibrio intra-extracelular (Trigo, 1993). Las lesiones observadas fueron similares a las obtenidas por Mansilla (1993) y Céspedes (2004).

El contenido en los quistes resultó letal en el $96 \%$ de los conejos inoculados con extracto de quistes pequeños y en el $68 \%$ en el caso de quistes grandes. Asimismo, se observó grandes diferencias en términos de supervivencia en conejos inoculados con $2.5 \mu \mathrm{g}$ de proteínas de macroquistes grandes o pequeños. Estos resultados confirman otros reportes que señalan que la dosis letal mínima para Sarcocystis sp. se encontraría por debajo de los $50 \mu \mathrm{g}$ de proteína/kg (Mansilla, 1993). En el presente estudio, la dosis letal mínima fue de $2.5 \mu \mathrm{g} / \mathrm{kg}$ para macroquistes grandes, en tanto que la dosis para macroquistes pequeños estaría en rangos menores. La diferencia de la toxicidad observada es probable que sea debida al estado 
de desarrollo que se encuentran los quistes más pequeños que contienen en su interior mayor número de metrozoitos que taquizoitos. Esta determinación de la dosis mínima letal es importante para la producción de antisueros y su uso posterior en diferentes pruebas de diagnóstico serológico (Romero, 2009).

\section{Conclusiones}

? Los macroquistes pequeños (1-3 mm) fueron más tóxicos que los macroquistes grandes $(>5 \mathrm{~mm})$, observándose manifestaciones clínicas post-inoculación.

? La dosis de $2.5 \mu \mathrm{g} / \mathrm{kg}$ de contenido de macroquiste grande de $S$. aucheniae no fue letal en los conejos incoluados.

\section{Literatura Citada}

1. Briggs M, Foreyt W. 1985. Sarcocystis in cattle. Cont Educ 6(7): 396-400.

2. Castro J. 1974. Sarcocystis aucheniae en llamas (Lama glama). Rev Inv Pec, IVITA 3: 91-92.

3. Céspedes C. 2004. Saneamiento y detoxificación de la carne de alpaca con Sarcocystis mediante tratamientos físicos apropiados para uso doméstico. Tesis de Médico Veterinario. Lima: Universidad Nac Mayor de San Marcos. 68 p.

4. Cordero del Campillo M, Rojas M, Fernández M, Sánchez M, Rodríguez S, López I. 1999. Parasitología Veterinaria. Madrid: Mc Graw-Hill. 968 p.

5. Cornejo RT, Chávez A, Leyva V, Falcón N, Panez S, Ticona D. 2007. Relación entre el tamaño de los macroquistes de Sarcocystis aucheniae y su viabilidad en Canis familiaris. Rev Inv Vet, Perú 18: 76-83.

6. Dubey JP, Speer CA, Fayer R. 1989. Sarcocystis of animals and man. Florida: CRC Press. 215 p.

7. Fayer R, Johnson AJ. 1973. Development of Sarcocystis fusiformis in calves infected with sporocysts from dogs. J Parasitol 59: 1135-1137.
8. Godoy R, Vilca M, Gonzáles A, Leyva $V$, Sam R. 2007. Saneamiento y detoxificación de la carne de llama (Lama glama) infectada con Sarcocystis aucheniae mediante cocción, horneado, fritura y congelado. Rev Inv Vet, Perú 18: 51-56.

9. Granados L, Vilca M, Sam R. 2007. Saneamiento y detoxificación de la carne de llama (Lama glama) infectada con Sarcocystis aucheniae mediante métodos químicos: Marinado, ahumando, curado seco y curado húmedo. Rev Inv Vet, Perú 18: 57-63.

10. Guerrero C, Hernández J, Alva J. 1967. Sarcocystis en alpacas. Rev Fac Med Vet UNMSM 21: 69-73.

11. Guinart N, López J. 1997. ¿Que sabemos de fiebre? Rev Cub Med Gen Integr 13 (2). [Internet] [20 marzo 2007]. Disponible en : http:// www.bvs.sld.cu/ revistas/ mgi/voll3_2_97/mgi09297.htm

12. Hiepe T. 1972. Enfermedad de la oveja. España: Ed. Acribia. 391 p.

13. Hiepe E, Lietzke LF, Scheibner G, Jungmann R, Hiepe T, Montag T. 1981 Untersuchungen zur toxischen wirkung von extrakten aus Sarcocystis ovifelis Macrozysten auf Kanichen. Mli Vet Med 36: 908-910.

14. Leguía G, Guerrero C, Sam R, Chávez A. 1989. Infección experimental de perros y gatos con micro y macroquistes de Sarcocystis de alpacas (Lama pacos). MV Rev Ciencias Vet 5(3): 10-13.

15. Leguía G. 2003. Infección experimental en primates no humanos (Saimiri boliviensis) y voluntarios humanos con micro y macroquistes de Sarcocystis de alpacas. Rev Acad Peru Cienc Vet 4(1): 11-15.

16. Mansilla D. 1993. Efecto histopatológico del lisado de macroquistes de Sarcocystis aucheniae en ratones, conejos y cobayos. Tesis de Médico Veterinario. Lima: Univ Nac Mayor de San Marcos. $60 \mathrm{p}$.

17. Nakamura T, Saito M, Shibata Y, Itagaki H. 1999. Induction of tumor 
necrosis factor a and nitric oxide in rabbits inoculated with a cyst extract of Sarcocystis cruzi. Vet Parasitol 38:236243.

18. Quiroz H. 2000. Parasitología y enfermedades parasitarias de animales domésticos. México: Limusa. 876 p.

19. Romero J. 2009. Respuesta inmune en conejos a dos tamaños de Sarcocystis aucheniae. Tesis de Médico Veterinario. Lima: Universidad Nac Mayor de San Marcos. 78 p.

20. Saito M, Taguchi K, Shibata Y, Kobayashi T, Shimura K, Itagaki $\mathrm{H}$. 1995. Toxicity and properties of the extract from Sarcocystis cruzi cysts. J Vet Med Sci 57: 1049-1151.
21. Saleque A, Bhatia B, Juyal P, Arman H. 1991. Toxicity of cyst extract of Sarcocystis from buffalo in rabbits and mice. Vet Parasitol 38: 61-65.

22. Sam R, Mansilla I, Morales C, Ramírez A. 1998. Efecto tóxico de macroquistes de Sarcocystis aucheniae en ratones, cobayos y conejos. Rev Inv Pec, IVITA 9(2): 11-18.

23. Trigo, 1993. Patología general veterinaria. $2^{\mathrm{a}}$ ed. México: Ed. Interamericana Mc Graw Hill. 242 p.

24. White S. 1998. Sarcocystis: A parasite endemic to Andean alpacas. Vol III. N ${ }^{\circ}$ 1. The Alpaca Registry Journal. [Internet], [16 setiembre 2008]. Disponible en: www.alpacaregistry.net/journal/win98j12.html 